\title{
Avoiding cardiopulmonary bypass in extracardiac cavopulmonary connection: Does it really matter?
}

\author{
Mohammad Ali Navabi, MD, ${ }^{a}$ Saideh M. Rastegar, MSN, ${ }^{a}$ Abdolrazagh Kiani, MD, ${ }^{b}$ Mahmood Gholam Ale \\ Mohammad, MD, ${ }^{\mathrm{a}}$ Parvin Akbari Asbagh, MD, ${ }^{\mathrm{a}}$ Mohammad Reza Mirzaaghayan, MD, ${ }^{\mathrm{a}}$ \\ Ali Pasha Meysamie, $\mathrm{PhD},{ }^{\mathrm{c}}$ and Reza Shabanian, $\mathrm{MD}^{\mathrm{b}}$
}

Objectives: We examined the effect of avoiding cardiopulmonary bypass on the early outcome variables after fenestrated extracardiac total cavopulmonary connection.

\begin{abstract}
Methods: Between May 2001 and January 2009, 102 patients with univentricular heart physiology underwent fenestrated extracardiac total cavopulmonary connection. Patients were divided into one of 2 groups: the cardiopulmonary bypass $(n=48)$ group and the no cardiopulmonary bypass $(n=54)$ group. In both groups there were patients with primary and staged fenestrated extracardiac total cavopulmonary connection. Duration of mechanical ventilation, pleural effusion, hemodynamic status, incidence of arrhythmia, and mortality were compared between the 2 groups.

Results: Both groups were matched, except for more cases of tricuspid atresia in the no cardiopulmonary bypass group $(P=.014)$ compared with other diagnostic morphologies and higher preoperative hemoglobin levels in the no cardiopulmonary bypass group $(P=.01)$. Avoiding cardiopulmonary bypass did not reveal any significant effect on postoperative outcomes. A cardiopulmonary bypass time of more than 120 minutes caused not only a meaningful increase in the mean of mechanical ventilation duration ( $35 \pm 9.6$ vs $13 \pm 2.1$ hours, $P=.026)$ but also increased the incidence of mechanical ventilation for more than 12 hours $(P=.04)$. Bypass time of more than 120 minutes did not have influence on any other postoperative variables.
\end{abstract}

Conclusion: Avoiding cardiopulmonary bypass in fenestrated extracardiac total cavopulmonary connection had no direct effect on the early outcome variables. (J Thorac Cardiovasc Surg 2010;139:1183-8)

Earn CME credits at

http://cme.ctsnetjournals.org

The early and midterm outcomes of surgical management in patients with a single ventricle have been influenced by many factors, especially by the modifications made to improve the flow dynamics in the Fontan operation since its first successful performance in $1971 .^{1}$ The dramatic improvements in morbidity and mortality have been credited to both better selection and technical modifications that include lateral tunnels, staging, fenestration, extracardiac conduits, and avoidance of cardiopulmonary bypass (CPB). However, various studies have yielded different results depending on the number of risk factors used as the

\footnotetext{
From the Department of Pediatric Cardiac Surgery, Imam Hospital ${ }^{\text {a }}$, the Department of Pediatric Cardiology, Children's Medical Center ${ }^{\mathrm{b}}$; and the Department of Biostatistics, ${ }^{\mathrm{c}}$ Tehran University of Medical Sciences, Tehran, Iran.

Disclosures: None.

Received for publication July 29, 2009; revisions received Sept 16, 2009; accepted for publication Oct 16, 2009; available ahead of print Dec 28, 2009.

Address for reprints: Mohammad Ali Navabi, MD, Department of Pediatric Cardiac Surgery, Imam Hospital, 62 Gharib St, 14194, Tehran, Iran (E-mail: manavabish@yahoo. com).

$0022-5223 / \$ 36.00$

Copyright (C) 2010 by The American Association for Thoracic Surgery

doi:10.1016/j.jtcvs.2009.10.031
}

selection criteria, the modifications implemented, and the definition of outcome variables. ${ }^{2-5}$ There are multiple studies that showed the feasibility of performing fenestrated extracardiac total cavopulmonary connection (FECTCPC) without the use of $\mathrm{CPB} .{ }^{6-11}$ However, the effect of avoiding $\mathrm{CPB}$ on early outcome has not been thoroughly examined. Furthermore, the majority of prior studies in which FECTCPC was performed without the use of CPB were staged, and the combined effects of primary versus staging with or without CPB have not been studied either. This report tries to address these issues in a group of matched patients after primary and staged FECTCPC.

\section{MATERIALS AND METHODS}

To assess the effect of CPB on the early outcome of patients palliated with extracardiac total cavopulmonary connection, 102 single-ventricle patients who were operated on by a single surgeon with this type of intervention from May 2001 to January 2009 were enrolled in the study.

Both demographic and clinical data during the pre-, intra-, and post-Fontan periods were gathered from a preformatted form and patients' medical records. The longer-term follow-up information was collected from follow-up records completed by cardiologists and the cardiac surgeon.

Demographic characteristics (age and weight), morphologic features (tricuspid atresia [TA] and non-TA), oxygen saturation in room air, pulmonary vascular resistance (PVR), and pulmonary artery (PA) pressure were compared between the $\mathrm{CPB}$ and no-CPB groups. Collected intraoperative information included superior vena cava (SVC), inferior vena cava (IVC), and PA pressures in addition to post-Fontan transpulmonary pressure gradient (TPG) changes. TPG equals the mean PA pressure minus the mean 


$$
\begin{aligned}
& \text { Abbreviations and Acronyms } \\
& \begin{aligned}
\text { CPB } & =\text { cardiopulmonary bypass } \\
\text { FECTCPC }= & \text { fenestrated extracardiac } \\
& \text { total cavopulmonary connection } \\
\text { ICU } & =\text { intensive care unit } \\
\text { IVC } & =\text { inferior vena cava } \\
\text { PA } & =\text { pulmonary artery } \\
\text { PVR } & =\text { pulmonary vascular resistance } \\
\text { SVC } & =\text { superior vena cava } \\
\text { TA } & =\text { tricuspid atresia } \\
\text { TPG } & =\text { transpulmonary pressure gradient }
\end{aligned}
\end{aligned}
$$

atrial pressure. Intraoperative TPG change was defined as the difference between the TPG values before and after extracardiac total cavopulmonary connection.

The outcome variables during the immediate postoperative period were duration of mechanical ventilation, duration of chest tube drainage in hours, persistent pleural effusion, arrhythmia, hemodynamic instability in the intensive care unit (ICU), and early mortality. We did not use the length of ICU stay as an outcome variable because it would be affected by many factors, such as the limited number of ward beds, which can delay patient transfer from the ICU to the ward. Mechanical ventilation duration is the time from the patient's arrival to the ICU until extubation. Persistent pleural effusion was defined as either when chest tubes were required to be in place for more than 7 days or the patient required repeated drainage after removal of the chest tubes. Arrhythmia was considered as any deviation from normal sinus rhythm, even transient deviation. Hemodynamic instability was defined as when the ejection fraction was less than $50 \%$, as determined by means of transthoracic echocardiographic analysis; inability to maintain hemodynamic stability despite conventional doses of inotropes (milrinone, $0.75 \mu \mathrm{g} \cdot \mathrm{kg}^{-1} \cdot \min ^{-1}$; epinephrine, $0.05-0.1 \mu \mathrm{g} \cdot \mathrm{kg}^{-1} \cdot \mathrm{min}^{-1}$ ); oliguria; or delayed rewarming for more than 3 to 5 hours. Mortality was considered early if death occurred within 30 days after the operation and late if death occurred more than 30 days after the operation. In-hospital mortality was defined as death occurring during the same hospitalization as the surgical procedure, regardless of when after the operation the death occurred. The number of deaths and operations would be the numerator and the denominator, respectively. ${ }^{12}$

\section{Patient Population}

A total of 102 patients palliated with FECTCPC were enrolled nonrandomly into the study. Reasons that CPB was used electively included an intracardiac procedure (eg, enlargement of either an atrial or ventricular septal defect) in 22 patients and absence of accessory pulmonary blood flow in 7 patients. Intraoperatively, we decided to use CPB in 17 patients because of the blood pressure decrease or arrhythmia and in 2 patients for the correction of cardiac lacerations resulting in massive bleeding.

We electively performed primary FECTCPC because of the older age of our patients, unless one of the following criteria for staging existed: post-PA banding, extensive PA reconstruction, intraoperative mean PA pressure of greater than $15 \mathrm{~mm} \mathrm{Hg}$, ventricular dysfunction, and azygous continuation of the IVC. This study was approved by the ethics committee of our institute. Informed consent was obtained for data extracting from patients' medical files.

\section{Statistical Analysis}

Our study was a clinical trial without randomization. Both univariate and multivariate analyses were used for data analysis. In univariate analysis continuous variables were tested for normality by using the KolmogorovSmirnov goodness-of-fit test. Normal data were compared among groups by means of independent samples $t$ tests. With nonnormal data, we used the Mann-Whitney test to compare 2 groups or the Kruskal-Wallis test to compare more than 2 groups. We showed the continuous results with means and standard deviations. The Pearson $\chi^{2}$ test and the Fisher's exact test were used to test the relationship between qualitative variables. Furthermore, the Mantel-Haenszel test was applied to adjust the effect of confounding variables. For data analysis, SPSS software (version 15; SPSS, Inc, Chicago, Ill) was used.

\section{Surgical Technique}

In the no-CPB technique 2 central venous line monitoring catheters were placed. One catheter was placed in either the right or left internal jugular vein, and the other was placed in either the right or left groin. After full heparinization, a temporary bypass, an SVC-atrial shunt, is constructed with 2 right-angled venous cannulas (SVC cannula of $14 \mathrm{~F}-24 \mathrm{~F}$ and atrial cannula of $24 \mathrm{~F}-32 \mathrm{~F}$ ) to crossclamp the single SVCs. In patients having bilateral SVCs, the veins could be simply crossclamped one by one without placing a temporary bypass. We chose the shortest possible cannula so as to minimize resistance while keeping it out of the field. Drainage of the SVC into the PA through temporary bypass tubing was helpful when no previous aortopulmonary shunt was present or when the previous right modified Blalock-Taussig shunt had to be replaced with the SVC-PA anastomosis. The SVC was connected to the PA after side-biting, finalizing the bidirectional cavopulmonary anastomosis. The azygous vein was ligated in the staged procedure and left intact in the primary Fontan operation. The enlarged noncardiac end of the main PA was then anastomosed to the selected polytetrafluoroethylene tube conduit $(14-22 \mathrm{~mm})$. We optimized the conduit dimensions in relation to the intraoperatively measured actual IVC diameter, with the upper limit of the conduit/IVC ratio being approximately 1.2. For most children, the conduit was 18 to $20 \mathrm{~mm}$ in diameter. Direct IVC cannulation at the most inferior site decompressed the IVC blood to the atrium through the temporary shunt (straight cannula, 18F-28F). The venoatrial junction was divided obliquely, leaving a short rim of atrial tissue around the IVC. Here mobilization of pericardial reflection was very helpful to achieve an adequate stump at both sides. The inferior end of the conduit was anastomosed end-to-end to the noncardiac end of the IVC. We selectively performed superior conduit anastomosis first to decrease IVC hypertension in the no-CPB group.

In older patients with a weight of greater than $40 \mathrm{~kg}$, temporarily bypassing the IVC to the atrium with the available cannula could result in IVC hypertension, postoperative jaundice, and increased serum amylase levels. The superior polytetrafluoroethylene conduit-PA anastomosis was performed first to minimize this risk. When the IVC drainage becomes inadequate and the IVC pressure exceeds $20 \mathrm{~mm} \mathrm{Hg}$, it is advised to side-bite the lateral IVC-atrial junction for end-to-side conduit-IVC anastomosis before proceeding to crossclamp and transect this junction. When the only source of blood flow to the lungs was a right aortopulmonary shunt, an IVC-PA pathway was reconstructed first. In the case that the shunt was placed near the hilum, it was possible to preserve the shunt temporally and implant the SVC onto the PA.

$\mathrm{CPB}$ was performed with ascending aortic and bicaval cannulation during moderate hypothermia (rectal temperature, $28^{\circ} \mathrm{C}-30^{\circ} \mathrm{C}$ ). Cardiac arrest with crystalloid cardioplegia was avoided unless a concomitant intracardiac operation was necessary. Cardioplegia was repeated at 20-minute intervals.

Fenestration was created in all cases with direct 4- to 6-mm side-to-side anastomosis of the extracardiac conduit to the atrium by using the punch technique and suturing atrial wall tissue around the fenestration distant from the fenestration's edge to ease possible device closure. After decannulation, protamine was administered only when hemostasis was not satisfactory. Bilateral pleural chest tubes were placed in all patients. We removed them once drainage was less than $2 \mathrm{~mL} \cdot \mathrm{kg}^{-1} \cdot \mathrm{d}^{-1}$ for each tube. It is 
speculated that this protocol minimizes the need for chest tube reinsertion after removal. ${ }^{13}$ We considered early postoperative anticoagulation therapy with warfarin to achieve a target international normalized ratio of 2 after discharge from the hospital.

\section{RESULTS}

\section{Preoperative and Perioperative Results}

Of 102 enrolled patients, $54(53 \%)$ had primary and 48 $(47 \%)$ had staged FECTCPC operations. The patient population was divided into those who did not receive CPB $(\mathrm{n}=$ $54[53 \%])$ and those who received CPB $(n=48[47 \%])$. No differences were found in age; weight; PVR; SVC, IVC, and PA pressures; and oxygen saturation between the no-CPB and CPB groups preoperatively (Table 1). Previous and concomitant operations in both groups are shown in Table 2.

There was a significant difference in the distribution of TA and non-TA between the 2 groups. There were 30 $(55 \%)$ TA and $24(45 \%)$ non-TA morphologies in the noCPB group versus $15(31 \%)$ TA and $33(69 \%)$ non-TA morphologies in the CPB group $(P=.014)$. Also, a significant difference was seen in the hemoglobin values between the 2 groups. In the no-CPB group the mean preoperative hemoglobin value was higher due to the higher prevalence of cyanotic patients (more patients without a previous bidirectional Glenn procedure) in this group (Table 1). Perioperative pressures did not show any difference between the 2 groups, neither in the SVC, IVC, and PA pressures nor in the TPG changes.

Six $(11 \%)$ patients in the no-CPB and $5(10 \%)$ in the CPB group had PA pressures of greater than $15 \mathrm{~mm} \mathrm{Hg}$. In addition, $3(6 \%)$ patients with severe atrioventricular valve regurgitation were in the CPB group at the time of Fontan completion. We had primary and staged Fontan completions in both groups (15 in the no-CPB group and 33 in the CPB group were staged, Table 2).

\section{Immediate Postoperative Results}

The mean duration of mechanical ventilation in the noCPB group was $25 \pm 78$ hours, and it was $23 \pm 30$ hours in the CPB group $(P=.84$, Table 3$)$. Because the median of mechanical ventilation time in our samples was 12 hours, the patients were analyzed in 2 categories of mechanical ventilation time: less than or equal to and greater than 12 hours. There was no significant difference in the mechanical ventilation duration between the no-CPB and CPB groups. Eighteen patients in both groups had mechanical ventilation times of greater than 12 hours $(P=.38)$.

The median, mean, and standard deviation of CPB time in the CPB group was 120,124 , and 42.6 minutes, respectively. CPB time of greater than 120 minutes caused a meaningful increase in the mean mechanical ventilation time $(35 \pm 9.6$ vs $13 \pm 2.1$ hours, $P=.026$ ) and also increased the incidence of mechanical ventilation time of greater than 12 hours (12 vs 6 patients, $P=.04)$. Bypass time of greater than $120 \mathrm{~min}$ utes did not influence any other postoperative variable.

There were no meaningful differences between the no-CPB and CPB groups in the incidence of arrhythmia, hemodynamic instability, or early mortality.

Twenty-two patients experienced hemodynamic instability in this setting: 12 in the no-CPB group and 10 in the CPB group $(P=.91)$. One early death caused by bleeding from a tracheostomy occurred in the no-CPB group, and 3 deaths caused by bleeding, arrhythmia, and intractable low cardiac output occurred in the CPB group. The remaining 18 patients were successfully treated with inotropic and afterload-reducing medications. However, 2 patients had transient left leg paresis, and 1 patient had myocardial infarction without hemodynamic consequences in the noCPB group. The in-hospital mortality rate was $6 \%$, with a $95 \%$ confidence interval of 0.00 to 0.13 for the CPB group and $1.9 \%$ with a $95 \%$ confidence interval of 0.00 to 0.05 for the no-CPB group.

Early in our study, there were 2 patients in whom the conduit was initially not fenestrated because of a low TPG $(<6$ $8 \mathrm{~mm} \mathrm{Hg}$ ), but later in the postoperative period, we had to take them back to the operating room because of prolonged and recurrent pleural effusion. Fenestration of the extracardiac conduit stopped the pleural effusion in these patients.

There were no meaningful differences between the no$\mathrm{CPB}$ and $\mathrm{CPB}$ groups in either chest tube drainage time (63 \pm 54 vs $72 \pm 50$ hours, $P=.53$ ) or incidence of persistent plural effusion $(7 / 54$ vs $6 / 48, P=.36)$. Moreover, the chest tube drainage time was not different in the primary and staged patients either ( $63 \pm 53$ vs $73 \pm 52$ hours, $P=$ .43). However, there was a trend toward an increased risk for occurrence of persistent plural effusion in the primary group (10/54 [18.5\%]) compared with that seen in the staged group (3/48 [6.2\%], $P=.064)$.

A 20 -year-old patient in the no-CPB group showed signs and symptoms of postoperative pancreatitis caused by the high IVC pressure in the off-pump technique. Serum amylase and liver enzyme levels were normalized in the next days, and the patient remained symptom free in the follow-up period.

A total of 92 patients were followed. At a mean of 27 months (range, 1-85 months), $89 \%$ of patients completed follow-up. All were in New York Heart Association class I, except 1 patient who was scheduled for Fontan takedown 3 years after FECTCPC (primary Fontan on CPB) because of high PVR and recurrent pleural effusion. One patient has gone through an uncomplicated delivery 7 years after FECTCPC (primary Fontan operation without CPB). No patients required late closure of the fenestration either surgically or with device occluders. Moreover, we did not notice any increasing incidence of arrhythmia in early or midterm follow-up. There was no mortality 6 months after surgical intervention, and since January 2006, we had no 
TABLE 1. Preoperative and perioperative variables in groups with and without CPB

\begin{tabular}{|c|c|c|c|c|}
\hline Phase of study & Variable & No-CPB group $(n=54)$ & CPB group $(n=48)$ & $P$ value \\
\hline \multirow[t]{13}{*}{ Preoperative } & Age (mo) & $121 \pm 77$ & $113 \pm 66$ & .54 \\
\hline & Weight $(\mathrm{kg})$ & $28.5 \pm 17.1$ & $28.6 \pm 16.0$ & .97 \\
\hline & $\operatorname{PVR}\left(\mathrm{WU} / \mathrm{m}^{2}\right)$ & $2.3 \pm 1.87$ & $1.8 \pm 2.33$ & .49 \\
\hline & SVC pressure $(\mathrm{mm} \mathrm{Hg})$ & $8.0 \pm 4.1$ & $9.9 \pm 4.6$ & .10 \\
\hline & IVC pressure $(\mathrm{mm} \mathrm{Hg})$ & $7.4 \pm 4.9$ & $6.6 \pm 3.4$ & .44 \\
\hline & PA pressure $(\mathrm{mm} \mathrm{Hg})$ & $10.7 \pm 4.2$ & $10.7 \pm 4.0$ & .98 \\
\hline & Oxygen saturation & $0.77 \pm 0.10$ & $0.77 \pm 0.07$ & .2 \\
\hline & Hemoglobin (g/dL) & $17.6 \pm 2.4$ & $16.2 \pm 2.1$ & .01 \\
\hline & Tricuspid atresia & $30(56 \%)$ & $15(31 \%)$ & .01 \\
\hline & Ventricular morphology & & & .1 \\
\hline & Right & $7(13 \%)$ & $14(29 \%)$ & \\
\hline & Left & $40(74 \%)$ & $30(63 \%)$ & \\
\hline & Undetermined & $7(13 \%)$ & $4(8 \%)$ & \\
\hline \multirow[t]{3}{*}{ Perioperative } & SVC pressure $(\mathrm{mm} \mathrm{Hg})^{*}$ & $14.0 \pm 4.7$ & $13.6 \pm 3.7$ & .66 \\
\hline & IVC pressure $(\mathrm{mm} \mathrm{Hg})^{*}$ & $13.9 \pm 3.9$ & $13.5 \pm 3.5$ & .61 \\
\hline & PA pressure $(\mathrm{mm} \mathrm{Hg})^{*}$ & $13.1 \pm 4.0$ & $12.1 \pm 3.2$ & .28 \\
\hline
\end{tabular}

$C P B$, Cardiopulmonary bypass; $P V R$, pulmonary vascular resistance; $S V C$, superior vena cava; $I V C$, inferior vena cava; $P A$, pulmonary artery. ${ }^{*}$ After fenestration.

early or late mortalities in the 33 patients undergoing operations during a period of 3 years. Six late deaths, $4(7.5 \%)$ in the no-CPB group and $2(4.4 \%)$ in the CPB group, occurred mainly as a result of the late referral of patients living in rural areas for drainage of pleural or pericardial effusion. The only variable related to late death was persistent pleural effusion $(P<.0001)$. Overall mortality was $10(9.8 \%), 5$ in each group $(P=.64)$. Neither the overall mortality nor the early mortality was influenced by using or avoiding CPB.

\section{DISCUSSION}

Current dissatisfaction with the early and long-term morbidity rates of children with single-ventricle pathology calls

TABLE 2. Previous and concomitant procedures with cavopulmonary connection and its type in patients with and without CPB

\begin{tabular}{lcc}
\hline \multicolumn{1}{c}{ Operations } & $\begin{array}{c}\text { No-CPB group } \\
(\mathbf{n}=\mathbf{5 4})\end{array}$ & $\begin{array}{c}\text { CPB group } \\
(\mathbf{n}=\mathbf{4 8})\end{array}$ \\
\hline Previous operation & & \\
$\quad$ Pulmonary artery band & 0 & $10(21 \%)$ \\
Interatrial septectomy & $4(7 \%)$ & $7(15 \%)$ \\
Shunt & $35(65 \%)$ & $27(56 \%)$ \\
Bidirectional Glenn procedure & $15(28 \%)$ & $33(69 \%)$ \\
Atrioventricular valve repair & $1(2 \%)$ & $1(2 \%)$ \\
Concomitant operations & & \\
Subaortic resection or & 0 & $9(19 \%)$ \\
$\quad$ VSD enlargement & & $5(10 \%)$ \\
Atrioventricular valve repair & 0 & $2(4 \%)$ \\
Pulmonary artery augmentation & $6(13 \%)$ & $8(17 \%)$ \\
Interatrial septectomy or & 0 & \\
$\quad$ ASD enlargement & & $15(31 \%)$ \\
Fontan (FECTCPC) operation & & $33(69 \%)$ \\
$\quad$ Primary & $39(72 \%)$ & \\
Staged & $15(28 \%)$ & \\
\hline
\end{tabular}

$C P B$, Cardiopulmonary bypass; $V S D$, ventricular septal defect; $A S D$, atrial septal defect; $F E C T C P C$, fenestrated extracardiac total cavopulmonary connection. for technical modifications in the surgical management of the disease. Although much has been achieved through better selection and technical modification, concerns about the morbidity and mortality rates of the procedure still remain. Many factors influence the early and late outcomes of patients undergoing the Fontan operation, and it is often difficult to assess the effect of each single modification on specific morbidity factors. ${ }^{2-5}$

Avoiding CPB during the Fontan operation has been practiced as an advantageous technical modification. ${ }^{6-11,14}$ Adverse effects of CPB have been studied. ${ }^{15,16}$ Some studies specifically showed its effects on proinflammatory and vasoactive substances that can potentially jeopardize the completed Fontan circulation and delay recovery. ${ }^{16}$ Tissue manipulation, heparin treatment, and circulation of the blood through the cannula are the possible causes for the release of inflammatory and vasoactive substances that should be further investigated. However, it is important that all of them also occur through the temporary decompression when $\mathrm{CPB}$ is avoided.

Our patient groups (CPB and no-CPB) were similar in several technical aspects, including having extracardiac conduits and fenestrations. However, differentiating characteristics do exist between the 2 groups. For instance, the factors that put the patients in the CPB group, such as the need for an intracardiac procedure, would add additional preoperative and perioperative risk factors to this group. Nevertheless, we found that these factors necessitating CPB did not adversely affect the patients' outcomes, including mechanical ventilation, arrhythmias, hemodynamic instability, and pleural effusion. However, prolonged CPB time of greater than 120 minutes increased the duration of mechanical ventilation.

We were also able to exclude the effect of other Fontan modifications on the selected outcome variables in our cohort. In addition, patients included in this study underwent 
TABLE 3. Postoperative variables in groups with and without CPB

\begin{tabular}{lllr}
\hline Postoperative variable & $\begin{array}{c}\text { No-CPB group } \\
(\mathbf{n}=\mathbf{5 4})\end{array}$ & $\begin{array}{c}\text { CPB group } \\
(\mathbf{n}=\mathbf{4 8})\end{array}$ & $\begin{array}{c}\boldsymbol{P} \\
\text { value }\end{array}$ \\
\hline $\begin{array}{l}\text { Mechanical ventilation } \\
\quad \text { duration (h) }\end{array}$ & $25 \pm 78$ & $23 \pm 30$ & .83 \\
Chest tube duration (h) & $63 \pm 54$ & $72 \pm 50$ & .53 \\
Persistent pleural effusion & $7(13 \%)$ & $6(13 \%)$ & .36 \\
Arrhythmia & $8(15 \%)$ & $12(25 \%)$ & .21 \\
Hemodynamic instability & $10(21 \%)$ & $12(22 \%)$ & .91 \\
Early mortality & $1(1.8 \%)$ & $3(6.2 \%)$ & .52 \\
Late mortality & $4(7.5 \%)$ & $2(4.4 \%)$ & .50 \\
\hline
\end{tabular}

$C P B$, Cardiopulmonary bypass.

surgical intervention over a relatively short time interval $(8$ years). This provided more uniformity in the preoperative selection criteria and postoperative care.

Prolonged pleural effusion remains one of the main unresolved complications in the early postoperative period. This complication has been reported in up to $37 \%$ in one report, when a higher TPG $(>12 \mathrm{~mm} \mathrm{Hg})$ was the basis for fenestration. ${ }^{17}$ Excessive pleural drainage as a predictor of poor outcome depends on multiple factors, and each contributing pathophysiology that gives rise to the pleural effusion might in turn be influenced by other specific modifications.

Because there was a trend toward an increased risk for occurrence of persistent plural effusion in the primary group (10 vs 3 patients in the staged group, $P=.064$ ), we looked at it in a different way out of our definition of pleural effusion. We added the patients requiring only one pleural tap after drain removal to the group with recurrent pleural effusion. Then the difference between the primary Fontan group and the staged group becomes significant $35 \%$ in the primary Fontan group vs $10 \%$ in the staged Fontan group, $P=.003)$. Because this fact could influence our comparison between the CPB and no-CPB groups, we performed a multivariable analysis to assess the effect of $\mathrm{CPB}$ and staging simultaneously. When CPB was used, the incidence of persistent pleural effusion was similar in the primary or staged group (3 patients in each group, $P=.3$ ), but if $\mathrm{CPB}$ was avoided, the incidence of persistent pleural effusion increased in the primary group (7 patients vs no patients in the staged group, $P=.07)$. Moreover, staging had no influence on our results except for the pleural effusion.

Although the lower preoperative oxygen saturation in patients without a previous bidirectional Glenn procedure (the primary FECTCPC group) might be a reason for the increased incidence of pleural effusion in this group, it could not be addressed statistically. Moreover, the increased incidence of persistent pleural effusion after avoiding CPB is difficult to interpret. The effect of other possible factors playing a role in persistent plural effusion, such as TA or non-TA and PVR of greater than 2 Woods units, were not significant with multivariate analysis, probably because of the dispersion of the cases.
Much has been said about the advantages of staging the Fontan operation. However, there are several disadvantages as well, especially when the second stage involves performing an extracardiac conduit from the IVC to the PA without using CPB. The adhesions make the operation longer and more tedious. This might be a reason for shifting the staged patients to CPB in the hands of some surgeons. In older patients, as in our cohort, the interim morbidity caused by the desaturation and ventricular volume overload and also the interim mortality are the other disadvantages of staging total cavopulmonary connection. It has been reported that staging would increase the sinoatrial node dysfunction and would also decrease PA sizes if the forward flow from the ventricle was not maintained. ${ }^{18,19}$

Based on previous studies, fenestration decreased the risk of early postoperative morbidity, such as low cardiac output and pleural effusion. ${ }^{20,21}$ Because we fenestrated extracardiac conduits in all cases, we were not able to compare the influence of this modification on the postoperative morbidity between the 2 groups. Our patients had no arterial embolization in both the early and midterm postoperative periods that could be due to lifelong anticoagulation in all cases.

A transected main PA leaves a potential space for emboli formation. Oversewing the cardiac end of the main PA without CPB might create a thrombogenic space between the pulmonary valves and the suture line at the transected portion of the main PA. Another possible immediate disadvantage of avoiding CPB while performing FECTCPC is the subsequent high IVC pressure in older patients. This complication might be avoided through the use of either the accessory decompression cannula routed from the groin toward the atrium or by side biting the lateral edge of the IVC-atrial junction to allow blood flow from the IVC to the atrium during superior conduit anastomosis.

\section{Study Limitations}

The older age of the patient population (mean \pm standard deviation, $117 \pm 72$ months) and the lack of a high-risk group with hypoplastic left heart make this study and its results not comparable with other studies. ${ }^{22}$ Moreover, the unavailability of extracorporeal membrane oxygenation and a ventricular assist device in our surgical unit are the other limitations that could influence the overall mortality.

\section{CONCLUSION}

Avoiding CPB in patients with FECTCPC was shown to be feasible and safe but had no direct effect on the patients' early outcomes. Although this modification seems attractive, today we have less interest in performing Fontan palliation without $\mathrm{CPB}$. Further studies involving a larger group of patients are required to confirm that avoidance of CPB will affect the pleural effusion in the primary Fontan operation or will decrease the effect of risk factors, such as higher 
PVR. More studies on the proinflammatory and vasoactive substances might be helpful to show the possible benefit of avoiding CPB in Fontan palliation.

\section{References}

1. Fontan F, Baudet E. Surgical repair of tricuspid atresia. Thorax. 1971;26:240-8.

2. Hosein RB, Clarke AJ, McGuirk SP, Griselli M, Stumper O, De Giovanni JV, et al. Factors influencing early and late outcome following the Fontan procedure in the current era. The "two commandments"? Eur J Cardiothorac Surg. 2007; 31:344-52.

3. Mitchell ME, Ittenbach RF, Gaynor JW, Wernovsky G, Nicolson S, Spray TL. Intermediate outcomes after the Fontan procedure in the current era. $J$ Thorac Cardiovasc Surg. 2006;131:172-80.

4. Yoshimura N, Yamaguchi M, Oshima Y, Oka S, Ootaki Y, Tei T, et al. Risk factors influencing early and late mortality after total cavopulmonary connection. Eur J Cardiothorac Surg. 2001;20:598-602.

5. Alphonso N, Baghai M, Sundar P, Tulloh R, Austin C, Anderson D. Intermediateterm outcome following the Fontan operation: a survival, functional and risk-factor analysis. Eur J Cardiothorac Surg. 2005;28:529-35.

6. Uemura H, Yagihara T, Yamashita K, Ishizaka T, Yoshizumi K, Kawahira Y. Establishment of total cavopulmonary connection without use of cardiopulmonary bypass. Eur J Cardiothorac Surg. 1998;13:504-7.

7. McElhinney DB, Petrossian E, Reddy VM, Hanley FL. Extracardiac conduit Fontan procedure without cardiopulmonary bypass. Ann Thorac Surg. 1998;66:1826-8.

8. Tam VK, Miller BE, Murphy K. Modified Fontan without use of cardiopulmonary bypass. Ann Thorac Surg. 1999;68:1698-703.

9. Yetman AT, Drummond-Webb J, Fiser WP, Schmitz ML, Imamura M, Ullah S, et al. The extracardiac Fontan procedure without cardiopulmonary bypass: technique and intermediate-term results. Ann Thorac Surg. 2002;74:S1416-21.

10. Petrossian E, Reddy VM, Collins KK, Culbertson CB, MacDonald MJ, Lamberti JJ, et al. The extracardiac conduit Fontan operation using minimal approach extracorporeal circulation: early and midterm outcomes. J Thorac Cardiovasc Surg. 2006;132:1054-63.
11. Tireli E, Ugurlucan M, Basaran M, Kafali E, Harmandar B, Sayin OA, et al. Extracardiac Fontan operation without cardiopulmonary bypass. J Cardiovasc Surg (Torino). 2006;47:699-704.

12. Welke KF, Shen I, Ungerleider RM. Current assessment of mortality rates in congenital cardiac surgery. Ann Thorac Surg. 2006;82:164-70.

13. Kumar SP, Rubinstein CS, Simsic JM, Taylor AB, Saul JP, Bradley SM. Lateral tunnel versus extracardiac conduit Fontan procedure: a concurrent comparison. Ann Thorac Surg. 2003;76:1389-96.

14. Shikata F, Yagihara T, Kagisaki K, Hagino I, Shiraishi S, Kobayashi J, et al. Does the off-pump Fontan procedure ameliorate the volume and duration of pleural and peritoneal effusions? Eur J Cardiothorac Surg. 2008;34:570-5.

15. Abu-Omar Y, Cader S, Guerrieri Wolf L, Pigott D, Matthews PM, Taggart DP. Short-term changes in cerebral activity in on-pump and off-pump cardiac surgery defined by functional magnetic resonance imaging and their relationship to microembolization. J Thorac Cardiovasc Surg. 2006;132:1119-25.

16. Mainwaring RD, Lamberti JJ, Hugli TE. Complement activation and cytokine generation after modified Fontan procedure. Ann Thorac Surg. 1998;65: 1715-20.

17. Gupta A, Daggett C, Behera S, Ferraro M, Wells W, Starnes V. Risk factors for persistent pleural effusions after the extracardiac Fontan procedure. J Thorac Cardiovasc Surg. 2004;127:1664-9.

18. Kostelka M, Hucín B, Tláskal T, Chaloupecký V, Reich O, Janousek J, et al. Bidirectional Glenn followed by total cavopulmonary connection or primary total cavopulmonary connection? Eur J Cardiothorac Surg. 1997;12:177-83.

19. Manning PB, Mayer JE Jr, Wernovsky G, Fishberger SB, Walsh EP. Staged operation to Fontan increases the incidence of sinoatrial node dysfunction. J Thorac Cardiovasc Surg. 1996;111:833-9.

20. Lemler MS, Scott WA, Leonard SR, Stromberg D, Ramaciotti C. Fenestration improves clinical outcome of the Fontan procedure: a prospective, randomized study. Circulation. 2002;105:207-12.

21. Bridges ND, Lock JE, Castaneda AR. Baffle fenestration with subsequent transcatheter closure. Modification of the Fontan operation for patients at increased risk. Circulation. 1990;82:1681-9.

22. Kim SJ, Kim WH, Lim HG, Lee JY. Outcome of 200 patients after an extracardiac Fontan procedure. J Thorac Cardiovasc Surg. 2008;136:108-16. 